\section{Subversão das classificações etárias de leitura pela enunciação editorial de Toujours la même histoire}

Subversion of reading recommendations based on age by Toujours la même histoire's editorial enunciation

Marc BARRETO BOGO (PUC-SP/Université de Limoges) marcbbogo@gmail.com

Recebido em: 31 de jul. de 2020. Aceito em: 02 de set. de 2020.
BARRETO BOGO, Marc. Subversão das classificações etárias de leitura pela enunciação editorial de Toujours la même histoire. Entrepalavras, Fortaleza, v. 11, n. 1, e2015, p. 1-20, jan.-abr./2021. DOI: 10.22168/22376321-12015.

Resumo: Toujours la même histoire é um exercício de criação literária que propõe narrar uma mesma história três vezes consecutivas, cada versão dedicada a um público leitor distinto: infantil, juvenil e adulto. Questionamonos: como a exploração da plasticidade do livro impresso e de seus discursos verbais apropria-se das convenções da literatura para essas três faixas etárias, problematizando-as? Objetivamos compreender como tais convenções são respeitadas ou subvertidas, especialmente em termos de exploração da plasticidade do projeto gráfico, das escolhas enunciativas dos três discursos verbais que concretizam narrativas semelhantes, mas não idênticas, e do uso das ilustrações que os acompanham. Metodologicamente, partimos do arcabouço teórico da Semiótica elaborada por A. J. Greimas e seus colaboradores, considerando especialmente os desenvolvimentos da Semiótica plástica. Ao final, compreendemos que, ao respeitar estritamente as regras de gênero nos seus enunciados plásticos e verbais, a obra rompe algumas tradições editoriais tratando exatamente dos mesmos temas e valores nas suas três versões, negando por meio da enunciação editorial as 
V. $11(1)$

$1-20$

jan-abr

2021

costumeiras indicações de leitura baseadas em idade cronológica. Toujours la même histoire, enfim, sugere que não há assuntos "adultos" que não possam ser abordados na literatura infanto-juvenil, e vice-versa.

Palavras-chave: Toujours la même histoire. Semiótica plástica. Gêneros literários.

Abstract: Toujours la même histoire is a creative literary exercise which consisted in retelling the same story three times in a row. Each version was dedicated to a different reading audience: children, youth and adults. We ask ourselves: how does the exploration of the printed book's plasticity and of its verbal discourses reflects the editorial conventions for these three age groups, at the same time debating them? We aim to understand how such conventions are respected or subverted, especially in terms of exploring the plasticity of the graphic design, the enunciative choices of the three verbal discourses that establish similar but not identical narratives, and the use of illustrations. Methodologically, we employ the theoretical framework of Semiotics, and particularly of Plastic Semiotics, developed by A. J. Greimas and his collaborators. We finally understand that precisely because of strict respect for editorial rules in its plastic and verbal discourses, this book breaks away from some publishing traditions by exploring exactly the same themes and values in its three versions, denying through its editorial enunciation the usual reading indications based on chronological age. Toujours la même histoire, in short, suggests that there are no "adult" subjects that cannot be addressed in children's literature, and vice versa.

Keywords: Toujours la même histoire. Plastic Semiotics. Literary genres.

\section{Introdução: um exercício literário}

Costumamos associar algumas características plásticas dos livros a certas convenções de gênero e de público destinatário. Por exemplo, um livro com papéis espessos, formato horizontal, farto uso de cores e de ilustrações seria normalmente associado à literatura infanto-juvenil, enquanto uma obra com papel de gramatura mais baixa, tipografia impressa em corpo menor e com quantidade de páginas mais numerosa poderia estar associada a leitores adultos. Essas são convenções plásticas que permitem ao grupo social identificar rapidamente certas qualidades da obra impressa, classificando-a deste ou daquele modo. No entanto, há muitos títulos que justamente partem dessas convenções de público e de gênero para subverter as regras, levá-las ao limite ou rearticulá-las em explorações discursivas e plásticas novas. Mas o que aconteceria se tentássemos contar uma mesma história respeitando as convenções editoriais da literatura para crianças, para jovens e para adultos? Como uma mesma narrativa se submeteria plasticamente às expectativas desses públicos distintos?

É justamente esse o exercício que se propõe a obra Toujours la même histoire ("Sempre a mesma história"), publicada pelas Éditions Non 
Standard em 2017. Já na autoria da obra, vemos como ela rompe algumas das tradições editoriais: o título é assinado em sua capa tanto por Jean Segui, escritor que efetivamente redigiu os textos verbais, quanto por Élodie Boyer, a dona da editora e responsável pelo "conceito e direção de criação" da obra. Além disso, a publicação conta com ilustrações de Josephin Ritschel (nome que também está presente na capa, mas em corpo menor, mais discreto) e design gráfico de Patrick Doan, um colaborador usual nas obras dessa editora. Do que se trata, exatamente, Toujours la même histoire? Vejamos como a obra é apresentada em sua quarta capa:

Toujours la même histoire conta três vezes a mesma história: uma história verdadeira, curta e ilustrada para as crianças; uma versão mais elaborada para os jovens; uma versão longa e atormentada para os adultos. Porque a leitura não é uma queda (o fim na verdade pouco importa), mas uma viagem. Este conto ilustrado conta uma história sobre o tema da partilha, onde o herói é ao mesmo tempo cruel e gentil. Boa viagem a Le Havre (SEGUI; BOYER, 2017; tradução nossa).

Ou seja, trata-se de uma mesma história contada três vezes sucessivas, em um mesmo volume (Fig. 1). Na trama, Vincent é um habitante idoso da cidade francesa Le Havre que faz amizade com um pombo à medida que o animal passa a frequentar seu quintal, ao mesmo tempo em que se irrita com a presença constante e indesejada de duas rolinhas. Contada em versão para crianças, a história é curta e possui muitas ilustrações coloridas. Logo em seguida, há uma segunda versão, para jovens, em que a mesma narrativa ganha mais detalhes, dividida dessa vez em dez capítulos, além de receber novas ilustrações. Por fim, uma terceira versão apresenta uma narrativa mais densa e extensa, com poucas e sóbrias ilustrações - em preto e branco, diga-se de passagem. 
V. 11 (1)

$1-20$

jan-abr

2021

Figura 1 - Capa e volume de Toujours la même histoire.

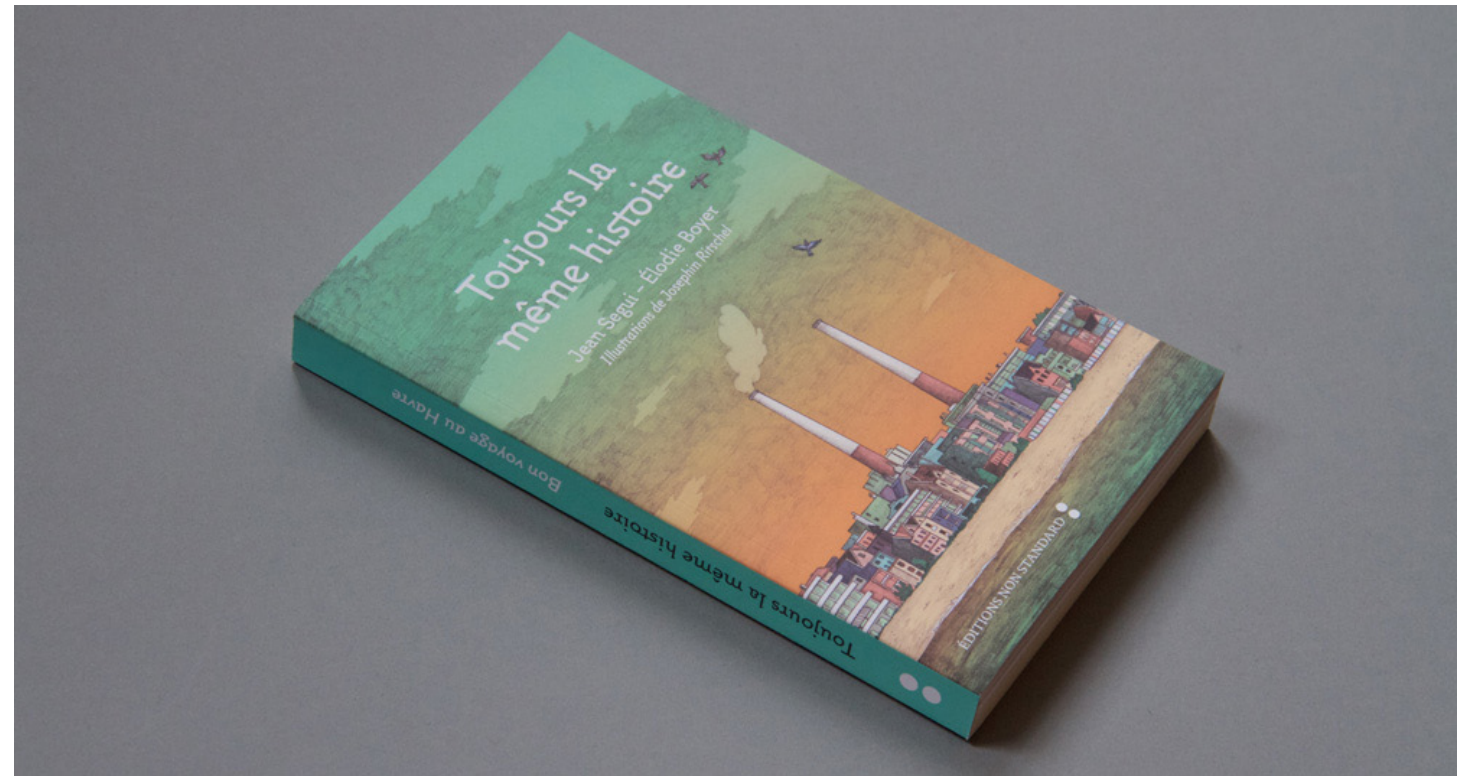

Fonte: Éditions Non Standad (2020).

Perguntamo-nos: como a exploração da plasticidade desse livro impresso e de seus discursos verbais apropria-se das convenções da literatura para essas três faixas etárias, problematizando-as? Sabe-se que a literatura de gênero infanto-juvenil costuma receber um tratamento discursivo e plástico bem diferente do que as obras voltadas para o público adulto. O conceito de "gênero" é aqui adotado na perspectiva de Steimberg:

Tem sido reiteradamente assinalado o caráter de instituição - relativamente estável - dos gêneros, que podem definirse como classes de textos ou objetos culturais, discrimináveis em toda linguagem ou suporte midiático, que apresentam diferenças sistemáticas entre si e que em sua recorrência histórica estabelecem condições de previsibilidade em distintas áreas de desempenho semiótico e intercâmbio social (STEIMBERG, 2013, p. 49; tradução nossa).

No entanto, apesar de certas regularidades ou "condições de previsibilidade" encontradas nas publicações voltadas para diferentes faixas etárias que instituem "classes de textos" - ou gêneros -, sabe-se também que as tradicionais indicações de leitura baseadas na idade cronológica dos leitores vêm sendo questionadas por escritores, teóricos e profissionais diversos ligados ao mercado editorial. Esse parece ser também o caso da obra aqui tomada para análise. Desse modo, objetivamos compreender como as convenções editoriais são respeitadas ou subvertidas, especialmente em termos de exploração da plasticidade do objeto literário, das escolhas enunciativas dos três 
discursos verbais que concretizam narrativas semelhantes, mas não idênticas, e do uso das ilustrações que os acompanham. Será que essas narrativas pensadas para o público infantil, juvenil e adulto são capazes de contar "sempre a mesma história"?

Visando dar conta das articulações entre o plano da expressão e o plano do conteúdo na obra analisada, metodologicamente partimos do arcabouço teórico da Semiótica elaborado ao longo de décadas por A. J. Greimas e seus colaboradores, que desenvolveram um modelo geral da produção do sentido ${ }^{1}$. Consideramos, em especial, os avanços da Semiótica plástica, desenvolvidos principalmente por Jean-Marie Floch e Felix Thürlemann, na França, e por Ana Claudia de Oliveira, no Brasil, entre outros investigadores semioticistas que tratam da Semiótica dos objetos, da estesia e dos suportes de escrita.

A relevância da escolha da obra Toujours la même histoire como corpus da investigação está em possibilitar a análise da relação entre a plasticidade do livro impresso e os gêneros literários, dois objetos teóricos já desenvolvidos individualmente em outros estudos semióticos cujas correlações, entretanto, não parecem esgotadas.

\section{Plasticidade do objeto literário}

Um livro é um objeto que possui certa densidade e que ocupa um lugar no espaço. A espacialidade e a materialidade do códice são conjugadas em um arranjo plástico da expressão que, no ato da leitura, é produtor de sentidos. Vejamos o que diz Klock-Fontanille sobre a importância dessa configuração formal do livro:

No caso da escrita alfabética ocidental, o livro, ou seja, a união em forma de códice de folhas de papel dobradas, é um suporte privilegiado desde a sua invenção, resistindo ainda à concorrência das telas. [...] Se o texto é aparentemente ligado a seu suporte de leitura, esse é também o caso de outra dimensão que podemos encontrar em um livro, a dimensão visual. Além disso, podemos notar uma ligação entre a forma do livro e seu conteúdo. Como a forma dos tabletes de argila podia indicar o seu conteúdo entre os sumérios, podemos frequentemente adivinhar o conteúdo de um livro, ou pelo menos o tipo de leitura a ele relacionado, a partir de seu formato - segundo nosso próprio grau de familiaridade com os diferentes objetoslivros (KLOCK-FONTANILLE, 2010, p. 23; tradução nossa).

\footnotetext{
${ }^{1}$ Esse modelo geral de que nos valemos está sintetizado no verbete "Gerativo (percurso -)" do Dicionário de Semiótica (GREIMAS; COURTÉS, 2011). A estrutura do percurso gerativo é reapresentada com numerosos exemplos provenientes do campo literário em obras como Caminhos da semiótica literária (BERTRAND, 2003), Elementos de análise do discurso (FIORIN, 2011) e Teoria semiótica do texto (BARROS, 2008).
} 
V. 11 (1)

1-20

jan-abr

2021

Esse "suporte privilegiado" que chamamos de livro pode dar pistas acerca de seu conteúdo já a partir da escolha do formato, como diz Klock-Fontanille. Temos a tendência de organizar os livros em gêneros ou categorias segundo sua plasticidade, os quais a autora chamou de "diferentes objetos-livros". Assim, a partir de nossa própria familiaridade com cada mercado editorial, podemos diferenciar logo pelo formato e pela aparência externa do volume diferentes tipos de leitura: livro de literatura, livro técnico, álbum, manual, dicionário, catálogo, livro infanto-juvenil e assim por diante.

O livro possui uma configuração tridimensional com a qual interagimos, manuseando-o, de modo que podemos considerá-lo um processamento do sistema espacial. Ao tratar do estudo dos objetos do ponto de vista da Semiótica, Landowski (2018) propõe que eles sejam analisados considerando-se os desenvolvimentos da Semiótica do espaço. Segundo o autor, a materialidade dos objetos (sua solidez relativa, seu grau de opacidade) resiste mais ou menos a nós quando os manuseamos, ao mesmo tempo em que eles "ocupam" uma determinada "porção de espaço". Diz Landowski: "É sempre como unidades caracterizadas espacialmente que os 'objetos' se destacam, se configuram, se transformam e também operam entre eles ou cooperam conosco" (LANDOWSKI, 2018; tradução nossa).

A Semiótica vem tratando os objetos da semiótica espacial através de uma série de categorias que, a princípio elaboradas para o estudo da arquitetura e do urbanismo, passaram a ser utilizadas na leitura de outros tipos de "espaços", como o espaço da página de um livro. O "espaço" é entendido, nessa abordagem, como um conjunto de qualidades sensíveis distribuídas espacialmente. Há uma série de oposições plásticas que organizam a espacialidade do códice e que são relevantes para a análise de um objeto literário, das quais podemos elencar algumas das mais importantes: superfície vs. volume, página ímpar vs. par, horizontalidade vs. verticalidade, anterioridade vs. posterioridade, entre outras.

Além das categorias plásticas espaciais, há certas categorias matéricas relativas ao suporte físico dos livros impressos que também podem ser exploradas em configurações produtoras de sentido. Os papéis e acabamentos produzidos podem apresentar oposições do tipo: fino vs. espesso, flexível vs. rígido, liso vs. rugoso, translúcido vs. opaco, colorido vs. acromático, toque quente vs. toque frio etc. 
Em Toujours la même histoire, algumas dessas qualidades matéricas são utilizadas como critério de diferenciação entre as três versões sucessivas da história. Assim, a primeira versão, para o público infantil, é impressa no papel Munken Print White $115 \mathrm{~g} / \mathrm{m}^{2}$, um papel rugoso e bastante espesso; a segunda versão, juvenil, é impressa no papel Milk White $85 \mathrm{~g} / \mathrm{m}^{2}$, um papel também rugoso, mas um pouco mais fino e flexível; a terceira versão, adulta, é impressa no Arcoprint Edizioni Arvorio $80 \mathrm{~g} / \mathrm{m}^{2}$, um papel bem mais fino, mas igualmente rugoso (Fig. 2). Assim, a categoria "espesso vs. fino" diferencia as três histórias, em um trajeto sensível que vai do papel mais espesso na versão infantil até o mais fino na versão adulta, enquanto a categoria "rugoso vs. liso" unifica as três versões, apresentando uma tatilidade rugosa em todos os papéis escolhidos para a obra.

Figura 2 - Diferença de materiais no miolo do livro.

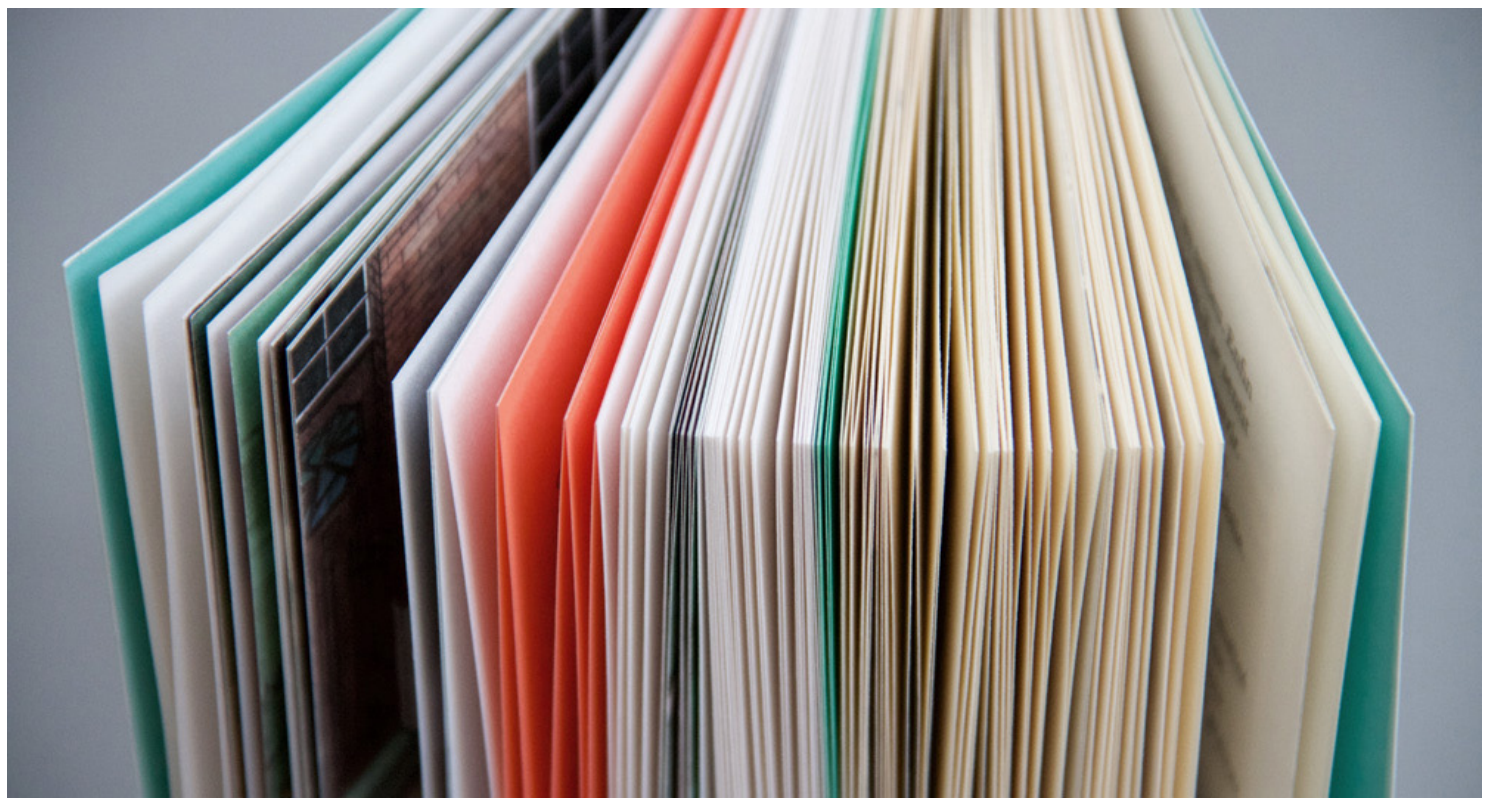

Fonte: Éditions Non Standad (2020).

Para dar conta da visualidade da obra que se imprime nesse espaço da página, podemos nos apoiar nas categorias já bem delimitadas pelos estudos da Semiótica plástica² ${ }^{2}$. Assim, o que observaremos em nossa análise são os formantes cromáticos, eidéticos e topológicos que configuram a manifestação visual da obra literária³.

\footnotetext{
${ }^{2}$ Uma síntese dessa abordagem plástica da visualidade pode ser encontrada no estudo "As semioses pictóricas", de Ana Claudia de Oliveira (2004). Já uma abordagem plástica dos projetos gráficos de livros encontra-se em "O design sensível do livro" (BOGO, 2018).

3 Veja-se os verbetes "Chromatique (catégorie -)", "Eidétique (catégorie -)" e "Topologique (catégorie -)" elaborados por Félix Thürlemann para o segundo volume do Dicionário de Semiótica (GEIMAS; COURTÉS, 1986).
} 
V. 11 (1)

1-20

jan-abr

2021

No cromatismo, analisamos tanto as cores do papel quanto as cores das tintas de impressão, através de oposições plásticas como saturado vs. dessaturado, brilhante vs. opaco, cores claras vs. escuras, entre outras. Em termos de formantes eidéticos, são relevantes as configurações plásticas no nível da forma, desde o próprio formato do livro, até as formas dos desenhos das famílias tipográficas utilizadas e o traçado das ilustrações e demais elementos gráficos, analisáveis por meio de oposições plásticas como reto vs. curvo, côncavo vs. convexo, grosso vs. fino, vertical vs. horizontal etc.

Essas cores e formas são topologicamente distribuídas no espaço da página, levando-se em conta categorias como central vs. periférico, alto vs. baixo, direita vs. esquerda, ou ainda a distribuição simétrica vs. assimétrica, próxima vs. distante, elementos em profusão vs. economia etc. Em nossa cultura ocidental, essas oposições marcam a ordem de leitura dos elementos dispostos no espaço impresso e os criadores conscientes dessa distribuição topológica podem tanto aproveitar-se do hábito de leitura para organizar o percurso do leitor segundo a ordem convencional, quanto para subverter certas normas.

Vejamos, então, como essas qualidades plásticas são exploradas na obra de Segui e Boyer (2017), e como elas estão articuladas ao sentido produzido no plano do conteúdo.

\section{Primeira versão: infantil}

A versão proposta para o público infantil chama-se Mon pigeon ("Meu pombo") e apresenta uma curta extensão (apenas 24 páginas), mas é fartamente ilustrada (Fig. 3). No uso do espaço das páginas, geralmente a escrita verbal e a ilustração aparecem lado a lado, com o desenho ocupando totalmente a página da direita ou da esquerda, enquanto a escrita ocupa a página oposta. Ilustração e escrita verbal são apresentados paralelamente na visibilidade da dupla-página e, em certas passagens, a ilustração chega a ocupar a totalidade da página da direita e da esquerda, com curtas sequências da escrita verbal sobrepostas à imagem, como aliás é a convenção nos livros ilustrados infantis. Os espaços periféricos não são utilizados para apresentar informações: não há fólio (numeração) nem títulos correntes e, mesmo nas ilustrações, os principais elementos figurativos são posicionados sempre na centralidade da imagem. Eis aí mais uma convenção da literatura para a infância que é aqui replicada: como as obras costumam ser breves, 
não há numeração nas páginas ou divisão em capítulos. A família tipográfica utilizada, Nicostrate, é pesada (apresenta traços grossos), não possui variação de espessura e alguns de seus caracteres possuem serifa grossa, outros não, o que confere uma variação e irregularidade no desenho das letras que faz com que a própria tipografia utilizada produza efeitos de sentido como "diversão" e "informalidade". Além disso, a tipografia é grafada em corpo grande (cerca de 16 pontos), o que também respeita a tradição editorial dos livros infantis.

Figura 3 - Algumas páginas da primeira versão da história.
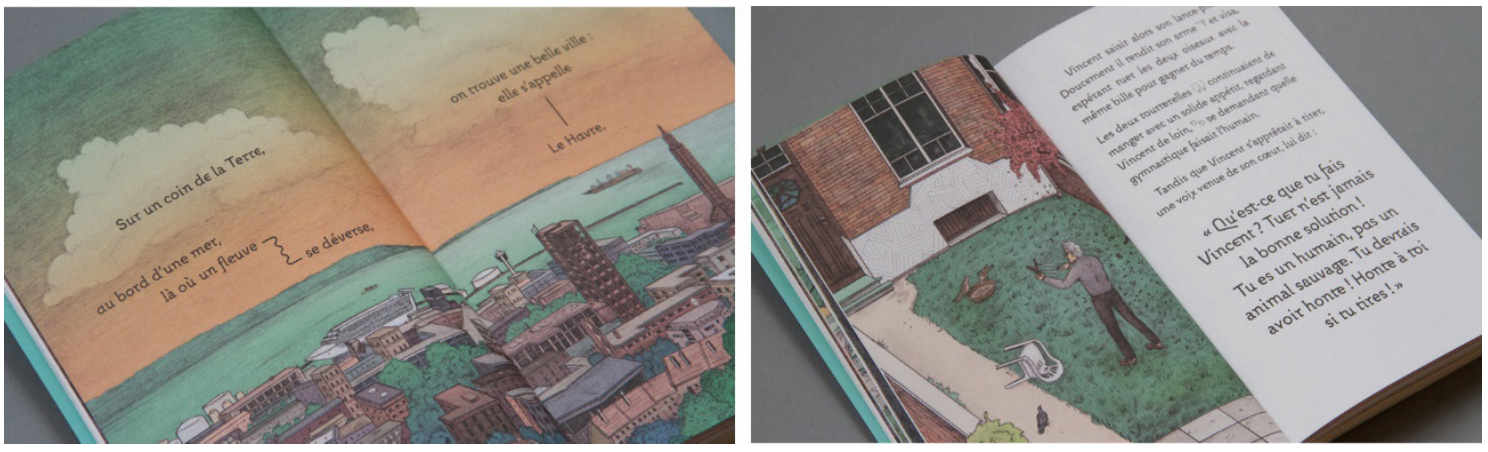

Fonte: Éditions Non Standad (2020).

Essa primeira versão da obra inicia pela narrativa verbal do modo como o universo foi criado por meio do Big Bang e, em seguida, narra como encontramos no planeta Terra uma bela cidade chamada Le Havre. Nela mora Vincent, um homem idoso que costuma dar migalhas de pão aos pássaros que visitam seu quintal. Um dia, ele faz amizade com um pombo velho e sujo, que apelida "Charlot". O pombo passa a frequentar o jardim para ser alimentado por Vincent, até o dia em que uma dupla de rolinhas chega para tentar comer os mesmos grãos e migalhas que haviam sido dispostos no pires. Charlot é obrigado a partir, já que não há espaço para ele, o que enfurece Vincent. Decidido a matar as duas rolinhas, ele produz um estilingue, treina sua mira atirando contra latas vazias e chega até mesmo a cavar um buraco para enterrar os pássaros. Um dia, ele vê as rolas afastarem Charlot novamente para comer os grãos e aponta o estilingue em sua direção. Porém, no momento crítico, uma voz interior o faz repensar suas ações e ele desiste de atirar. Após refletir muito durante a noite, no dia seguinte Vincent decide comprar um pires enorme, enche-o de grãos e assim tanto Charlot quanto as rolas podem comer juntos, tranquilamente.

A história é apresentada tanto pela escrita verbal quanto pelas ilustrações, que seguem fielmente os acontecimentos narrados, em uma 
V. $11(1)$ $1-20$ jan-abr 2021 duplicidade ou redundância narrativa. As ilustrações são claras, com traços finos (vs. grossos) e cores puras ( $v s$. mescladas), o que remete à forma simples e direta como a história é contada no sistema verbal. Os desenhos utilizam muitas linhas retilíneas e uma distribuição ortogonal, o que remete à espacialização do discurso: a cidade de Le Havre, onde se passa a trama, é marcada por sua arquitetura modernista, única na França.

As figuras que estão concretizadas no discurso tanto pelo sistema verbal quanto pelo visual dizem respeito a elementos da natureza e do cotidiano da vida na cidade: planeta, Terra, animais, homens, cidade, casa, jardim, velho, pássaros, pombo, rola, penas, grama, árvore, folhas, floresta, migalhas, grãos, pires, boca, bico, jornal, vizinho, faca, estilingue, balas de aço, lata, carro, garagem etc. Essas figuras concretizam alguns temas principais da obra, esses mais abstratos: natureza, humanidade, vida em sociedade, solidão, velhice, amizade, morte, partilha, bondade e maldade.

Já em um nível fundamental, essa primeira versão da obra nos apresenta uma axiologia de valores articulada em torno de duas oposições semânticas: /coletividade/ vs. /individualidade/ e /natureza/ vs. /cultura/. À medida que o personagem principal repensa suas inclinações violentas e decide partilhar os grãos entre todos os pássaros, é o valor da coletividade que está sendo apresentado como "moral da história". A narrativa de Vincent é, metonimicamente, a narrativa de como a humanidade deve aprender a lidar com os seres da natureza, respeitando toda forma de vida.

\section{Segunda versão: juvenil}

A versão voltada ao público jovem chama-se À prendre ou à donner ("Pegar ou doar") e apresenta uma extensão bem maior do que a precedente (90 páginas). Nessa variante, o espaço periférico da página é bem utilizado, já que há diversas notas de rodapé ao longo do texto, bem como numeração. As notas explicam, com bom humor, certas palavras que são importantes na narrativa e que supostamente não fariam parte do vocabulário usual de um jovem. Assim, por exemplo, uma nota explica que tyran ("tirano") não é uma versão reduzida de Tyrannosaurus, mas alguém que "abusa de sua posição dominante". Também no espaço da página percebemos certos trechos que são destacados em corpo maior, o que cria uma hierarquia de leitura entre bloco de texto, notas explicativas 
e destaques, que complexifica a disposição do sistema verbal (em relação à versão anterior, para crianças). Há níveis diferentes de leitura, como em uma revista ou site, aproximando-se assim do repertório de consumo midiático do público jovem. Na espacialidade, a página ímpar marca inícios de capítulos (dez no total), inserindo descontinuidades, ou seja, pequenas pausas na leitura, que dessa vez não se faz mais de um fôlego só.

No projeto gráfico dessa segunda versão, vemos que as margens são mais estreitas que na versão precedente, além do corpo de texto também ser menor (Fig. 4). A tipografia utilizada no bloco de texto chama-se Anselm e apresenta serifas finas e variação de espessura no traçado das letras, o que a localiza no grupo das famílias tipográficas romanas oldstyle, o mais habitual para obras de leitura contínua (romances, por exemplo). No entanto, a tipografia utilizada nos títulos dos capítulos (chamada Infini) apresenta grande variação na altura dos caracteres, desenhando palavras cuja linha de base ziguezagueia verticalmente, construindo certo efeito de sentido de "informalidade" que se contrapõe à tipografia mais formal dos blocos de texto. Ou seja, a combinação tipográfica nos posiciona entre o lúdico e o sério, entre o infantil e o adulto.

Figura 4 - Páginas da segunda versão da história.
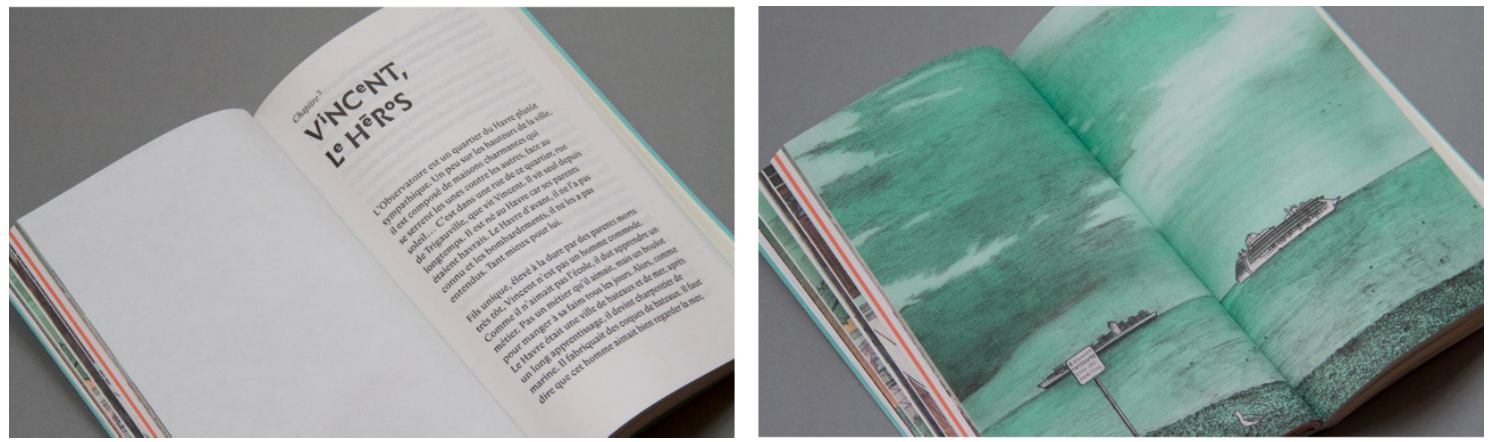

Fonte: Éditions Non Standad (2020).

As ilustrações da versão juvenil estão localizadas em um bloco único de páginas, composto por oito ilustrações consecutivas intercaladas entre o início da história, que apresenta a cidade de Le Havre, e a continuidade que narra as interações entre o protagonista Vincent, o pombo Charlot e as rolinhas. Essa segunda versão detalha um pouco mais a história de Le Havre, explicando como a cidade foi bombardeada durante a Segunda Guerra e reconstruída em seguida, além de ilustrar várias de suas localidades. As ilustrações têm como 
V. $11(1)$

1-20

jan-abr

2021

tema único a urbe, figurativizando elementos arquitetônicos sem a presença de seres humanos ou animais. As imagens são monocromáticas (versus o policromatismo da versão anterior), contando com ainda mais traços retilíneos. Constrói-se assim um percurso visual que lembra os desenhos mais racionais de um manual didático ou de uma enciclopédia, abandonando a ludicidade da versão infantil.

No plano do conteúdo, temos aproximadamente os mesmos eventos principais sendo narrados, com algumas pequenas modificações (por exemplo, em vez de produzir um estilingue de madeira para tentar matar as rolinhas, Vincent compra um estilingue feito de aço com um comerciante de armas). O estilo discursivo é mais bem humorado e irreverente que a primeira versão, além de melhor detalhar a trama, dada a extensão maior do texto. No entanto, os temas explorados são exatamente os mesmos da primeira versão, apenas com maior aprofundamento. Desse modo, nos primeiros capítulos, por exemplo, discute-se mais a questão da convivência entre os homens, aprofundando os temas da vida em sociedade e da humanidade, acrescentando na discussão a questão da desigualdade social que o planeta enfrenta. A temática da solidão também é mais explorada nessa versão, em capítulos que detalham a rotina solitária de Vincent, seu passado (narrando sua aposentadoria e a superação de uma depressão), seu passatempo (a marcenaria) e até informando que ele já possui um espaço marcado no cemitério SainteMarie. O tema da velhice também é mais desenvolvido, a partir de uma comparação explícita entre o velho pombo Charlot, com suas penas desajeitadas, e o protagonista aposentado, com seu cabelo revolto.

No nível profundo das estruturas sêmio-narrativas, os valores fundamentais articulados na versão juvenil são os mesmos que já havíamos encontrado na versão infantil: /coletividade/ vs. /individualidade/ e /natureza/ vs. /cultura/. A última fala da história, por exemplo, ressalta claramente o valor da coletividade: "Vocês terão que aprender a compartilhar', diz Vincent, com as mãos nos quadris" (SEGUI; BOYER, 2017, p. 134; tradução nossa).

\section{Terceira versão: adulta}

Em seu título Petite morte dans l'âme ("Pequena morte na alma"), a última versão da narrativa, voltada ao público adulto, já indica que assume em seu discurso um tom mais denso e pessimista. Não há mais notas divertidas de rodapé ou destaques no sistema verbal 
que criam hierarquias de leitura, mas apenas um grande bloco de texto contínuo, em uma coluna única. A extensão mais longa da história (124 páginas) é distribuída novamente em dez capítulos, os quais se iniciam sempre na página ímpar. A oposição entre posicionamento central vs. periférico continua sendo explorada no projeto gráfico, já que as poucas ilustrações estão localizadas geralmente nas extremidades das páginas, sangrando para fora do volume. As margens são tão estreitas quanto na versão juvenil, porém o corpo do texto é ainda menor (cerca de 12 pontos). A tipografia utilizada (Mercury) é uma serifada tradicional, discreta, empregada tanto nos títulos quanto no bloco de texto, o que confere um efeito de sentido de "seriedade" a essa versão, especialmente em comparação com os jogos tipográficos das versões precedentes.

As oito ilustrações que estão distribuídas ao longo dessa versão mostram principalmente detalhes da arquitetura da cidade onde se passa a história, partes de construções que não são tão facilmente reconhecíveis quando comparadas com os desenhos precisos das versões anteriores. As ilustrações são totalmente dessaturadas, ou seja, impressas em preto e branco, o que contribui para o efeito de sentido de sobriedade dessa terceira versão da história (Fig. 5).

Figura 5 - Páginas ilustradas da terceira versão.
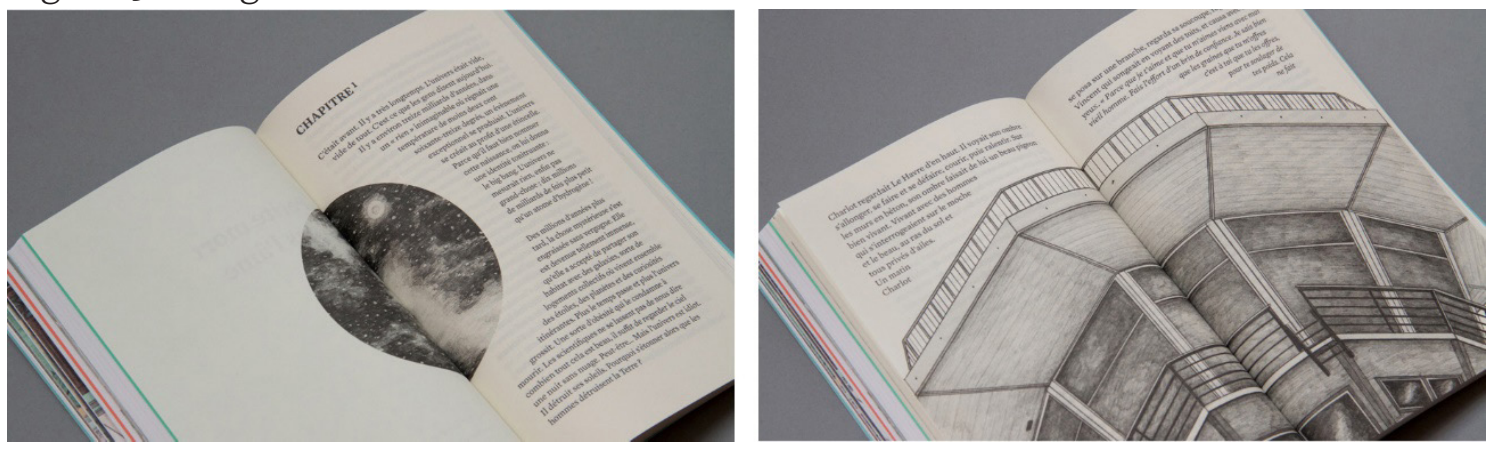

Fonte: Éditions Non Standad (2020).

A terceira versão é a que apresenta o nível discursivo do sistema verbal mais enriquecido figurativamente, com um detalhamento maior dos personagens e cenários. Assim, o passado e a personalidade de Vincent são bem mais desenvolvidos e ficamos sabendo, por exemplo, que ele não se lembra mais da última vez em que foi feliz e que ainda guarda rancor de seus pais, assim como de sua ex-mulher e filha, que o abandonaram. A descrição de Charlot também é mais rica em traços figurativos: o pombo caminha com dificuldades, quase que usando uma pata só, um olho seu está parcialmente fechado, o outro parece vítreo, 
V. $11(1)$

$1-20$

jan-abr

2021 suas penas são felpudas etc. Essa versão "para adultos" também possui passagens reflexivas mais longas, apresentando encadeamentos de percursos temáticos.

Na interação entre narrador e narratário, a história adulta apresenta uma curiosa passagem metalinguística em que o narrador se mostra consciente do desafio que é escrever um mesmo relato "para três faixas etárias diferentes", o que não ocorreria nas versões anteriores. Há, ao longo do texto, algumas citações de falas de escritores e personalidades célebres, como Sartre, Oscar Niemeyer e Jorge Luis Borges, construindo relações intertextuais explícitas. Essas operações discursivas - metadiscursividade e intertextualidade - são então apresentadas na obra como traços característicos do conteúdo literário "adulto".

No entanto, apesar do maior desenvolvimento no nível discursivo, a trama continua essencialmente a mesma, com algumas passagens a mais (por exemplo, a descrição de uma visita reflexiva de Vincent à Igreja Saint-Joseph) e algumas diferenças em relação às versões anteriores (em vez de cavar um buraco no jardim para enterrar as rolas, ele abre um espaço em seu congelador, pensando em cozinhálas). A principal diferença nos eventos narrados é que, nessa versão, o velho pombo morre no capítulo final. O mesmo conjunto de temas é explorado (natureza, humanidade, vida em sociedade, solidão, velhice, amizade, morte, partilha, bondade e maldade) e os mesmos valores fundamentais podem ser encontrados na base do texto.

\section{Nas convenções, a ruptura}

Toujours la même histoire parte das convenções editoriais das publicações para os públicos infantil, juvenil e adulto, arriscando-se a contar uma história única, cada vez mais detalhadamente, etapa a etapa. Assim, a versão supostamente infantil não tem páginas numeradas, é mais ilustrada, com desenhos mais coloridos etc., reforçando as convenções do gênero. A segunda versão apresenta ilustrações mais sóbrias, numeração nas páginas, notas de rodapé e uma divisão em capítulos que, teoricamente, não seria apropriada a um livro infantil. Já a terceira versão, "para adultos", quase não possui ilustrações (as quais, quando presentes, são impressas em preto e branco), é impressa em corpo de texto visivelmente menor e, no sistema verbal, utiliza um tom de voz muito mais grave para contar a mesma narrativa, cuja 
trama é na verdade bastante simples. Trata-se de um conjunto de escolhas plásticas que respeitam as expectativas das publicações para cada público, construindo no projeto gráfico uma aparência que faz o enunciatário crer estar realmente diante de uma obra proposta ora para crianças, ora para jovens, ora para adultos.

No entanto, vimos que há uma invariante temática que resiste aos arranjos plástico-figurativos do projeto gráfico, das ilustrações e da dimensão verbal empregados em cada uma das três versões. Podese dizer que a obra explora a chamada "elasticidade do discurso" ": ao mesmo tempo em que percebemos uma tendência para a expansão verbal e para a correspondente condensação visual, à medida em que se avança nas faixas etárias pressupostas, notamos que são mantidas certas equivalências semânticas entre as três versões.

O conjunto de escolhas plásticas da obra pode ser sintetizado em uma homologação semissimbólica ${ }^{5}$ entre a categoria do conteúdo /infância/ vs. /maturidade/ e a categoria da expressão "ampliação vs. redução" (Quadro 1). Empregamos aqui uma estratégia similar à utilizada por Floch (2009) em seu estudo sobre o sincretismo na publicidade, em que o autor organiza as relações entre as dimensões visual e verbal de um mesmo texto publicitário por meio de um único esquema visual de homologações entre categorias. Na leitura de nosso quadro, no entanto, deve-se reconhecer que, entre os dois termos contrários de cada categoria, localizam-se ainda as escolhas plásticas relativas à versão juvenil, caracterizadas pelo meio caminho entre um e outro termo dos pares de opostos.

\footnotetext{
${ }^{4}$ No verbete "Elasticidade do discurso" do Dicionário de Semiótica, Greimas e Courtés (2011) definem esse fenômeno como a possibilidade de que unidades discursivas de dimensões diferentes possam ser consideradas "semanticamente equivalentes", em especial ao sofrerem operações de expansão e de condensação.

${ }^{5} \mathrm{O}$ semissimbolismo pode ser entendido como a correspondência entre uma categoria do plano da expressão e uma categoria do plano do conteúdo. A noção foi desenvolvida sobretudo nos estudos de semiótica visual por Jean-Marie Floch, especialmente no primeiro capítulo de Petites mythologies de l'œil et de l'esprit (FLOCH, 1985).
} 
V. $11(1)$

$1-20$

jan-abr

2021

Quadro 1 - Homologação entre categorias da expressão e do conteúdo.

\begin{tabular}{|c|c|c|c|}
\hline & $\begin{array}{r}\text { Papel }\left(115 \mathrm{~g} / \mathrm{m}^{2}\right): \\
\text { espesso }\end{array}$ & VS. & $\begin{array}{l}\text { Papel }\left(80 \mathrm{~g} / \mathrm{m}^{2}\right) \text { : } \\
\text { fino }\end{array}$ \\
\hline & $\begin{array}{r}\text { Ilustrações: } \\
\text { saturação } \\
\text { policromatismo }\end{array}$ & $\begin{array}{l}\text { VS. } \\
\text { VS. }\end{array}$ & $\begin{array}{l}\text { Ilustrações: } \\
\text { dessaturação } \\
\text { acromatismo }\end{array}$ \\
\hline & $\begin{array}{r}\text { Margens }(1,7 \mathrm{~cm}): \\
\text { largo }\end{array}$ & vs. & $\begin{array}{l}\text { Margens }(1,3 \mathrm{~cm}) \text { : } \\
\text { estreito }\end{array}$ \\
\hline & $\begin{array}{r}\text { Corpo de texto: } \\
\text { grande }\end{array}$ & vs. & $\begin{array}{l}\text { Corpo de texto: } \\
\text { pequeno }\end{array}$ \\
\hline Plano da expressão & ampliação & vs. & redução \\
\hline Plano do conteúdo & /infância/ & vs. & /maturidade/ \\
\hline & $\begin{array}{r}\text { Discurso } \\
\text { verbal sucinto, } \\
\text { com menor } \\
\text { detalhamento } \\
\text { figurativo e } \\
\text { temático }\end{array}$ & vs. & $\begin{array}{l}\text { Discurso verbal } \\
\text { alongado, } \\
\text { com maior } \\
\text { detalhamento } \\
\text { figurativo e } \\
\text { temático }\end{array}$ \\
\hline
\end{tabular}

Fonte: o autor.

A ruptura nas tradições editoriais que faz dessa obra um "exercício literário" se dá justamente pelo respeito estrito das regras de gênero. Se na expressão e mesmo no discurso verbal a obra segue à risca todas as convenções esperadas para livros infantis, juvenis e adultos, no conteúdo ela subverte as expectativas ao tratar exatamente dos mesmos temas e valores nas três versões da obra. O que esse livro nos mostra é que se há alguma diferença aparente entre títulos para públicos de faixas etárias diversas, todos eles podem efetivamente abordar os mesmos percursos temáticos e concretizar os mesmos valores de base. Assim, temas em geral considerados mais "adultos", como a morte, a velhice e a solidão, são também tratados na versão infantil; além disso, os valores que fundamentam a construção da obra, ou seja, o valor da "natureza" e o valor da "coletividade", que talvez pudessem ser encontrados com mais frequência em obras infantojuvenis, erigem igualmente a construção do sentido na versão adulta. Toujours la même histoire propõe a hipótese de trabalho de que não há "temas para adultos" que não possam ser abordados para um público infantil, e vice-versa.

Há um jogo intrincado entre o que está enunciado na plasticidade e na dimensão verbal da obra e os sentidos construídos pela própria enunciação editorial, que une as três versões da história em um objeto só, a ser lido em sua integralidade. Na reunião desses 
enunciados visuais e verbais, o que fica claro é a intenção comunicativa de um paralelo entre as três versões. Tomamos a expressão "enunciação editorial" conforme sua delimitação por Emmanuel Souchier:

O conceito de enunciação editorial remete à elaboração plural do objeto textual. Ele anuncia uma teoria da enunciação polifônica do texto produzido ou proferido por qualquer instância que possa intervir na concepção, realização ou produção do livro e, mais amplamente, da palavra escrita. [...] Pensemos: autor, editor, diretor de coleção, corretor, revisor, ilustrador, designer gráfico, tipógrafo, digitador, impressor, parceiros oficiais ou mecenas... aos quais convém acrescentar o fabricante de papel, o encadernador, sem mencionar o livreiro ou o distribuidor que às vezes intervêm a montante na cadeia de produção. Cada um desses parceiros deixa um rastro de sua intervenção, o qual é devidamente codificado, acordado ou simplesmente responde às práticas ou aos usos. Em graus variados, esses traços ou "marcas da enunciação editorial" moldam e constituem a identidade do texto (SOUCHIER, 1998, p. 141-142; tradução nossa).

Essa enunciação editorial é, em Toujours la même histoire, o pôr em conjunto ilustrações, discurso verbal e projeto gráfico do livro. Ao dispor sequencialmente as três versões da história, o enunciador propõe ao enunciatário uma reflexão sobre as semelhanças e diferenças entre elas. Embora cada enunciado visual ou verbal exiba individualmente claras diferenças entre as propostas para as três faixas etárias, a enunciação que os reúne em um mesmo objeto literário propõe uma reflexão sobre tais diferenças, levando o enunciatário a concluir que os temas e valores são os mesmos nas três versões, sem diferenciação entre as idades de leitura previstas. A diferença de faixa etária que é afirmada nos enunciados é negada na enunciação.

Há assim, na totalidade da obra, uma leitura fundada na oposição /ser/ versus/parecer/. Ao enfatizar na concretização plástica e nos estilos discursivos, em sua aparência mais imediata, as diferenças entre os gêneros, o que o livro faz é justamente manter valores constantes em suas três versões, rompendo ou borrando as diferenças entre públicos. Estabelece-se um jogo entre o ser (dizer) e o parecer (dito), pois o que é dito no enunciado não se afirma na enunciação. Esse mecanismo produz um efeito de sentido que José Luiz Fiorin (1988) aponta como dissimulação. Segundo o autor: "[a dissimulação] deve ser aqui entendida como a reunião de dois modos de ver um fato, como a maneira de mostrar a ambigüidade de alguma coisa e as múltiplas maneiras de interpretá-la" (FIORIN, 1988, p. 59). 
V. 11 (1)

1-20

jan-abr

2021

O livro analisado opera um procedimento que é o de desacordo entre as instâncias do enunciado e da enunciação, pois afirma algo no enunciado que é negado na enunciação. Ainda segundo Fiorin (1988, p. 59): "Quando se afirma no enunciado e se nega na enunciação, temos a figura que a retórica denominou antífrase". Enfatizamos que a enunciação, em nosso caso, não é aquela enunciada cujas marcas estão presentes em cada versão da história, mas sim a enunciação editorial que une as três versões em uma só totalidade de sentido. Na quarta capa da obra, promete-se uma história "para as crianças", uma versão diferente "para os jovens" e ainda uma terceira "para os adultos", mas o que se diz sem ter dito é que não há diferença profunda entre as três histórias e que essa diferenciação segundo as idades dos leitores nada mais é que mera convenção editorial. O próprio nome da editora, Éditions Non Standard, é uma pista de que essa obra deve ser lida justamente em suas provocações às normatizações vigentes.

\section{Conclusão: o livro em suas reconfigurações plásticas}

A título de conclusão, cabe ainda uma breve reflexão sobre o que a obra de Segui e Boyer propõe em termos de reconfiguração do suporte "livro". Para isso, assumimos a diferenciação entre os chamados "suporte material" e "suporte formal", conforme sistematizado por Fontanille (2005) a partir do estudo de Klock-Fontanille(2005): enquanto o suporte material diz respeito aos elementos matéricos necessários para fixar temporalmente um discurso (o "objeto" em si), o suporte formal diz respeito à seleção de limites e às regras de inscrição nesse suporte material (ou seja, sua sintaxe), segundo as práticas de produção e de interpretação de cada cultura. O livro de literatura é interpretado tanto como um suporte material quanto formal. Cada gênero editorial possui certas convenções relativas tanto a sua materialidade (a partir dos papéis e formatos empregados podemos mais ou menos prever o tipo de conteúdo nele inscrito) quanto a suas regras de combinação (desde o uso de imagens ou ilustrações, passando pelas margens da página, cores utilizadas na impressão, corpo e família tipográfica adotada etc.). Toujours la même histoire parte de três convenções distintas de suporte material e as combina em um só objeto, resultando em uma obra que emprega três papéis de qualidades e espessuras diferentes, o que por si só já é um desvio da norma. Além disso, em termos do suporte formal, vimos que cada versão obedece às regras sintáxicas de inscrição 
esperadas para cada tipo de público, o que justamente ajuda a construir o /parecer/ de diferenciação entre as idades dos leitores.

No entanto, ao fazer uso rigoroso das convenções do suporte material e formal do livro infantil, juvenil e adulto para comunicar os mesmos valores, o enunciador diz sem ter dito que não importam tanto assim as diferenças de faixa etária. Esse objeto tomado para análise mostra-nos que os enunciados plásticos e verbais de um livro podem tanto afirmar quanto desafiar as convenções de gênero na literatura, mas que, mesmo ao adotar uma dessas posturas, a enunciação editorial ainda pode reafirmar ou contradizer o enunciado.

Compreender as regras de cada perfil de público pode ser interessante justamente para entendermos como elas podem ser rompidas ou subvertidas, o que em Toujours la même histoire é feito com sutil ironia por meio da antífrase. Segundo Steimberg, ao discorrer sobre a condição de mudança dos gêneros: "o que também pode tornar interessante uma taxonomia (como, precisamente, a dos gêneros discursivos) é sua condição cambiante e, como tal, seu caráter indicador privilegiado da mobilidade de uma cultura" (STEIMBERG, 2013, p. 93; tradução nossa).

Na esteira de autores literários que trabalham com técnicas de restrição para sua escrita criativa (como os famosos exercícios de escrita do grupo OuLiPo, por exemplo), a obra analisada parte das regras estritas estabelecidas para cada faixa etária de público leitor e, ao respeitar explicitamente as normas editoriais, chega a uma publicação que propõe algo novo. Se, nos enunciados, a história se submete às convenções plásticas e de escrita de cada público, vemos que no conteúdo não há fronteiras rígidas entre eles. Afinal, é possível contar de maneiras muito diferentes "sempre a mesma história".

\section{Referências}

BARROS, D. L. P. Teoria semiótica do texto. 4. ed. São Paulo: Ática, 2008.

BERTRAND, D. Caminhos da semiótica literária. Tradução Grupo CASA. Bauru, SP: Edusc, 2003.

BOGO, M. B. O design sensível do livro. Actes Sémiotiques [En ligne], n. 121, 2018.

ÉDITIONS NON STANDARD. Toujours la même histoire. 2020. Disponível em: https://editions-non-standard.com/books/toujours-la-meme-histoire. Acesso em: 05 mar. 2020. 
V. $11(1)$

1-20

jan-abr

2021

FIORIN, J. L. As figuras de pensamento: estratégia do enunciador para persuadir o enunciatário. Alfa, n. 32, p. 53-67, 1988.

FIORIN, J. L. Elementos de análise do discurso. 15. ed. São Paulo: Contexto, 2011.

FLOCH, J.-M. Petites mythologies de l'œil et de l'esprit: pour une sémiotique plastique. Paris-Amsterdã: Hadès-Benjamins, 1985.

FLOCH, J.-M. Semiótica plástica e linguagem publicitária: análise de um anúncio da campanha de lançamento do cigarro "News". Tradução J. L. Fiorin. In: OLIVEIRA, A. C.; TEIXEIRA, L. (Orgs.). Linguagens na comunicação: desenvolvimentos de semiótica sincrética. São Paulo: Estação das Letras e Cores, p. 145-167, 2009.

FONTANILLE, J. Écritures: du support matériel au support formel. In: ARABYAN, M.; KLOCK-FONTANILLE, I. (Eds.). L'écriture entre support et surface. Paris: L'Harmattan, p. 183-200, 2005.

GREIMAS, A. J.; COURTÉS, J. Sémiotique: Dictionnaire raisonné de la théorie du langage: Tome 2: compléments, débats, propositions. Paris: Hachette, 1986.

GREIMAS, A. J.; COURTÉS, J. Dicionário de Semiótica. 2. ed. Vários tradutores. São Paulo: Contexto, 2011.

KLOCK-FONTANILLE, I. L'écriture entre support et surface : l'exemple des sceaux et des tablettes hittites. In: ARABYAN, M.; KLOCK-FONTANILLE, I. (Eds.). L'écriture entre support et surface. Paris: L'Harmattan, p. 29-52, 2005.

KLOCK-FONTANILLE, I. Des supports pour écrire: d'Uruk à Internet. Français d'aujourd'hui, n. 170, p. 13-30, 2010.

LANDOWSKI, E. Note préliminaire. Eléments pour une sémiotique des objets (matérialité, interaction, spatialité). Actes Sémiotiques [En ligne], n. 121, 2018.

OliVEIRA, A. C. As semioses pictóricas. In: OLIVEIRA, A. C. (Org.). Semiótica Plástica. São Paulo: Hacker, p. 115-158, 2004.

SEGUI, J.; BOYER, É. Toujours la même histoire. Ilustrações de Josephin Ritschel. Le Havre: Éditions Non Standard, 2017.

SOUCHIER, E. L'image du texte pour une théorie de l'énonciation éditoriale. Les cahiers de médiologie, n. 6, p. 137-145, 1998.

STEIMBERG, O. Semióticas: Las semióticas de los géneros, de los estilos, de la transposición. Buenos Aires: Eterna Cadencia Editora, 2013. 